\title{
A Second Case of Gobello Nevus Syndrome
}

\author{
Gianluca Tadini ${ }^{\mathrm{a}, \mathrm{b}} \quad$ Luisa Carlotta Rossi ${ }^{\mathrm{a}} \quad$ Elisa Faure $^{\mathrm{a}}$ \\ Francesca Besagni $^{c}$ Vinicio Boneschi ${ }^{a}$ Susanna Esposito ${ }^{b}$ \\ Michela Brena ${ }^{a}$ \\ ${ }^{a}$ Dermatology Unit and ${ }^{b}$ Pediatric Highly Intensive Care Unit, Department of \\ Pathophysiology and Transplantation, Fondazione IRCCS Ca' Granda, Ospedale Maggiore \\ Policlinico, University of Milan, Milan, and 'Section of Dermatology, Department of \\ Clinical and Experimental Medicine, Parma University, Parma, Italy
}

\section{Key Words}

Epidermal nevus syndrome - Bone abnormalities · Follicular hyperkeratosis · Clinodactyly · Tufted hair folliculitis

\begin{abstract}
An uncommon type of epidermal nevus characterized by hyperpigmented hyperkeratotic bands following a Blaschko-linear pattern and generalized follicular hyperkeratosis were observed in a 17-year-old male patient who additionally showed tufted hair folliculitis on the scalp and clinodactyly of the fifth finger of both hands. The combination of epidermal nevus with skeletal abnormalities was first described by Gobello et al. [Dermatology 2000;201:5155] as a new epidermal nevus syndrome that was named after the first author of this work. Our case shows identical clinical and histopathological features and represents the second case of this rare syndrome reported in the literature.

(C) 2016 The Author(s)

Published by S. Karger AG, Basel
\end{abstract}

\section{Introduction}

In 1968, Solomon et al. [1] named the coexistence of epidermal nevi with various extracutaneous manifestations 'epidermal nevus syndrome'. Many different kinds of epidermal nevus syndromes are known, including Schimmelpenning syndrome, Proteus syndrome, CHILD syndrome, nevus comedonicus syndrome [2, 3], Becker nevus syndrome [4], phakomatosis pigmentokeratotica [5] and PTEN-associated nevus [6], originating from different genetic mechanisms. In 2000, Gobello et al. [7] described an unusual case of epidermal nevus

\section{KARGER}

Gianluca Tadini

Department of Pathophysiology and Transplantation, Fondazione IRCCS Ca Granda, Ospedale Maggiore Policlinico, University of Milan, Via Pace 9 IT-20122 Milan (Italy)

E-Mail gtadinicmce@unimi.it 
characterized by systematized hyperpigmented bands of nonepidermolytic hyperkeratosis with increased hairiness superimposed to background generalized follicular hyperkeratosis. The patient was a 16-year-old boy who additionally showed some skeletal abnormalities, such as hemihypoplasia of limbs, brachydactyly, clinodactyly of the fifth fingers and onycodystrophy. Moreover, on X-ray examination, shorter left radius and ulna, pelvic obliquity and a short left femur were noted.

We herein report an identical case of epidermal nevus with follicular hyperkeratosis associated with skeletal anomalies.

\section{Case Presentation}

The index patient is a 17-year-old boy born from nonconsanguineous parents, who presented with hyperpigmented, rough streaks following a nonobvious, broad-band Blaschkolinear distribution. These skin lesions had been visible since birth and had progressively extended to large parts of the right side of his body. No other family member had similar skin lesions or suffered from any cutaneous disease. On physical examination, a follicular hyperkeratosis was noted on his entire body, more pronounced in the darker skin patches (fig. 1). On his scalp, an area of scarring alopecia characterized by perifollicular erythema and follicular hyperkeratosis was noted with a tufted-like folliculitis pattern (fig. 2). In addition, the patient showed clinodactyly of the fifth finger of both hands, but more evidently on the left side. On X-ray examination, clinodactyly was confirmed, while no other skeletal abnormalities were found (fig. 3). In particular long and pelvic bones were normal. Cytogenetic analysis of peripheral blood lymphocytes revealed a normal karyotype of $46, \mathrm{XY}$.

Histopathological examination of biopsies obtained from the hyperpigmented bands and 'background' skin were both characterized by hyperkeratosis with basket-woven configuration in the stratum corneum and an irregular epidermal acanthosis with papillomatosis. In the papillary and perifollicular dermis, the blood vessels were dilated and surrounded by scattered lymphocytic infiltrates (fig. 1A, fig. 1B). In addition, in the section obtained from the 'background' skin, thinned and dystrophic hair shafts could be noted (fig. 1A). The section derived from the darker bands showed instead an orthokeratotic stratum corneum, more pronounced hair follicles clustered with an evident follicular hyperkeratosis, infundibular keratinic plugs and irregular distribution of melanin pigment in the basal cell layer (fig. 1B).

\section{Discussion}

We report the case of a boy who showed Gobello nevus syndrome. Our patient presented two peculiar cutaneous signs: hyperpigmented and rough broad bands following a Blaschko linear pattern on the right side of his body and generalized follicular hyperkeratosis on the 'background' skin. It is reasonable to assume that this unusual type of epidermal nevus originates from a mechanism known as loss of heterozygosity: the follicular hyperkeratosis on the entire skin surface of the patient would reflect heterozygosity for the mutation, while the hyperpigmented bands ('superimposed' epidermal nevus) would visualize loss of the corresponding normal allele with consequent, even more accentuated, follicular hyperkeratosis in these areas. This second event, occurring at an early stage of embryonic development, would give rise to a clone of cells that become homozygous for the hypothetical mutation. The scalp lesion showed a typical vortex pattern and moreover, the presence of 
Tadini et al:: A Second Case of Gobello Nevus Syndrome

multiple hairs emerging from a single dilated follicular opening, configuring a tufted hair-like folliculitis. The patient also presented clinodactyly of the fifth finger of both hands, confirmed by X-ray examination (fig. 3). No other skeletal abnormalities were found, and all laboratory findings were normal.

Based upon both particular clinical appearance and identical histological pattern, we conclude that our patient represents the second case of Gobello nevus syndrome reported in the literature.

\section{Statement of Ethics}

The authors have no ethical conflicts to disclose. The patient has given his consent, including for the use of the pictures.

\section{Disclosure Statement}

The authors have no conflicts of interest to disclose.

\section{References}

1 Solomon LM, Fretzin DF, Dewald RL: The epidermal nevus syndrome. Arch Dermatol 1968;97:273-285.

- Happle R: Lethal genes surviving by mosaicism: a possible explanation for sporadic birth defects involving the skin. J Am Acad Dermatol 1987;16:899-906.

3 Happle R: The categories of cutaneous mosaicism: a proposed classification. Am J Med Genet A 2016;170:452-459.

4 Happle R, Koopman RJ: Becker nevus syndrome. Am J Med Genet 1997;68:357-361.

5 Happle R, Hoffmann R, Restano L, Caputo R, Tadini G: Phacomatosis pigmentokeratotica: a melanocyticepidermal twin nevus syndrome. Am J Med Genet 1996;65:363-365.

6 Happle R: Linear Cowden nevus: a new distinct epidermal nevus. Eur J Dermatol 2007;17:133-136.

7 Gobello T, Mazzanti C, Zambruno G, Chinni LM, Happle R: New type of epidermal nevus syndrome. Dermatology 2000;201:51-55. 


\section{Case Reports in Dermatology}

\begin{tabular}{l|l}
\hline Case Rep Dermatol 2016;8:85-90 \\
\hline DOI: $10.1159 / 000445675$ & $\begin{array}{l}\text { (c) 2016 The Author(s). Published by S. Karger AG, Basel } \\
\text { www.karger.com/cde }\end{array}$ \\
\hline
\end{tabular}

Tadini et al.: A Second Case of Gobello Nevus Syndrome
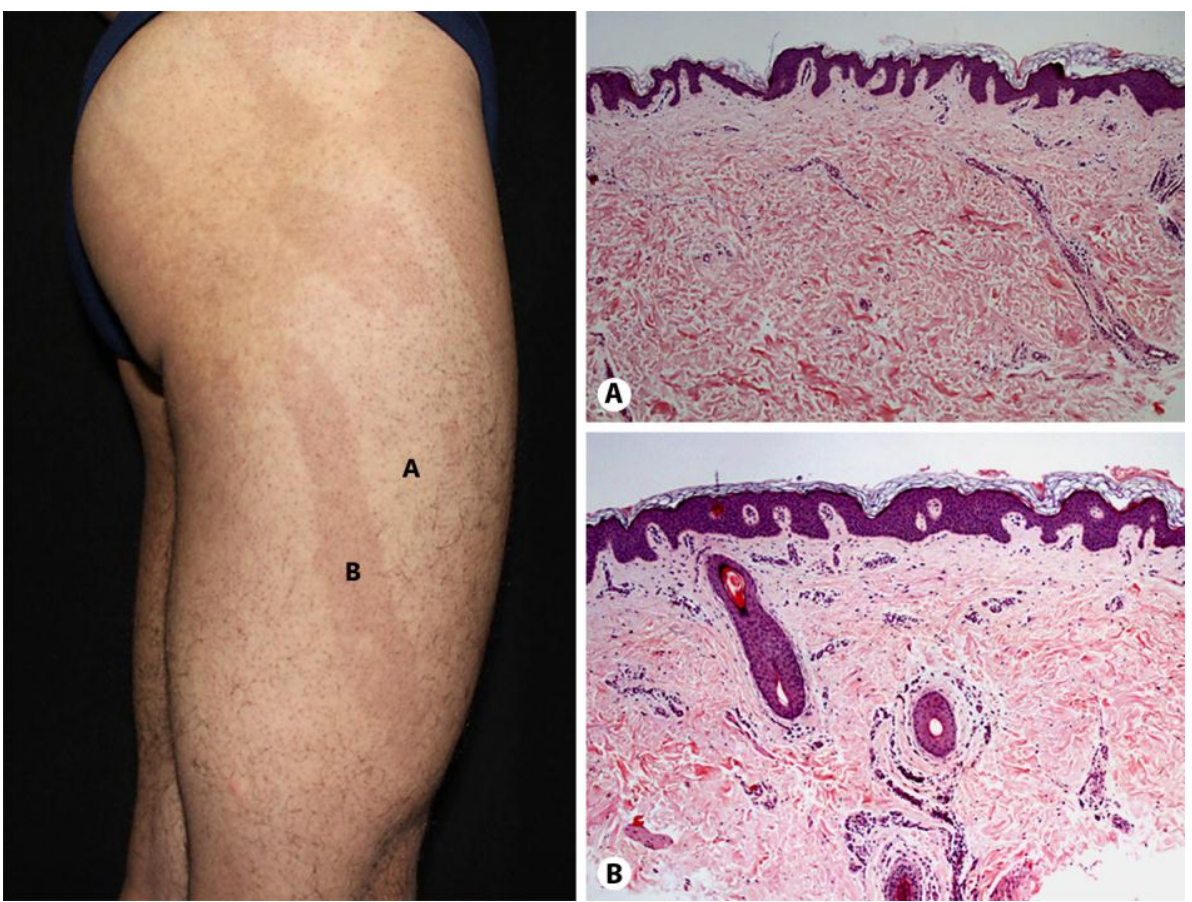

Fig. 1. The patient presented hyperpigmented and rough bands following a Blaschko-linear pattern on the right side of the body and generalized follicular hyperkeratosis on the 'background' skin. Both histological sections showed hyperkeratosis with basket-woven configuration in the stratum corneum, irregular epidermal acanthosis with papillomatosis and dilated blood vessels surrounded by scattered lymphocytic infiltrates. A Thinned and dystrophic hair shafts in the section of the 'background' skin. B Orthokeratotic stratum corneum, hair follicles clustered with an evident follicular hyperkeratosis, infundibular keratinic plugs and irregular distribution of melanin pigment in the basal cell layer in the section of the nevus. 


\section{Case Reports in Dermatology}

Tadini et al.: A Second Case of Gobello Nevus Syndrome

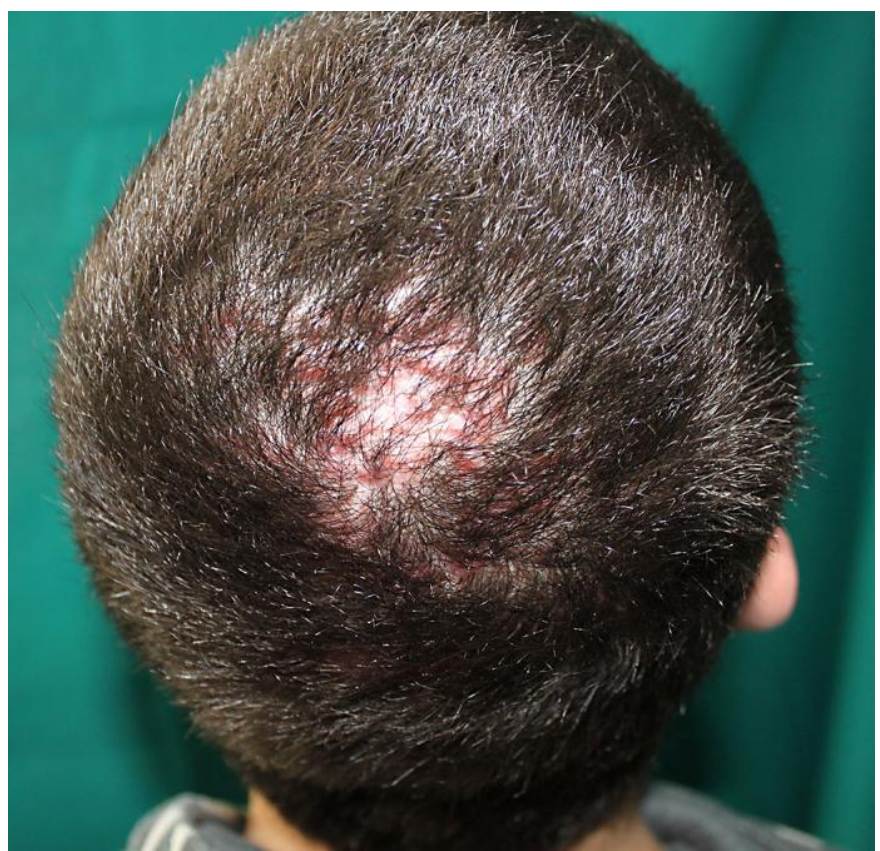

Fig. 2. Tufted hair folliculitis on the scalp, a patch of alopecia characterized by perifollicular erythema and follicular hyperkeratosis. 

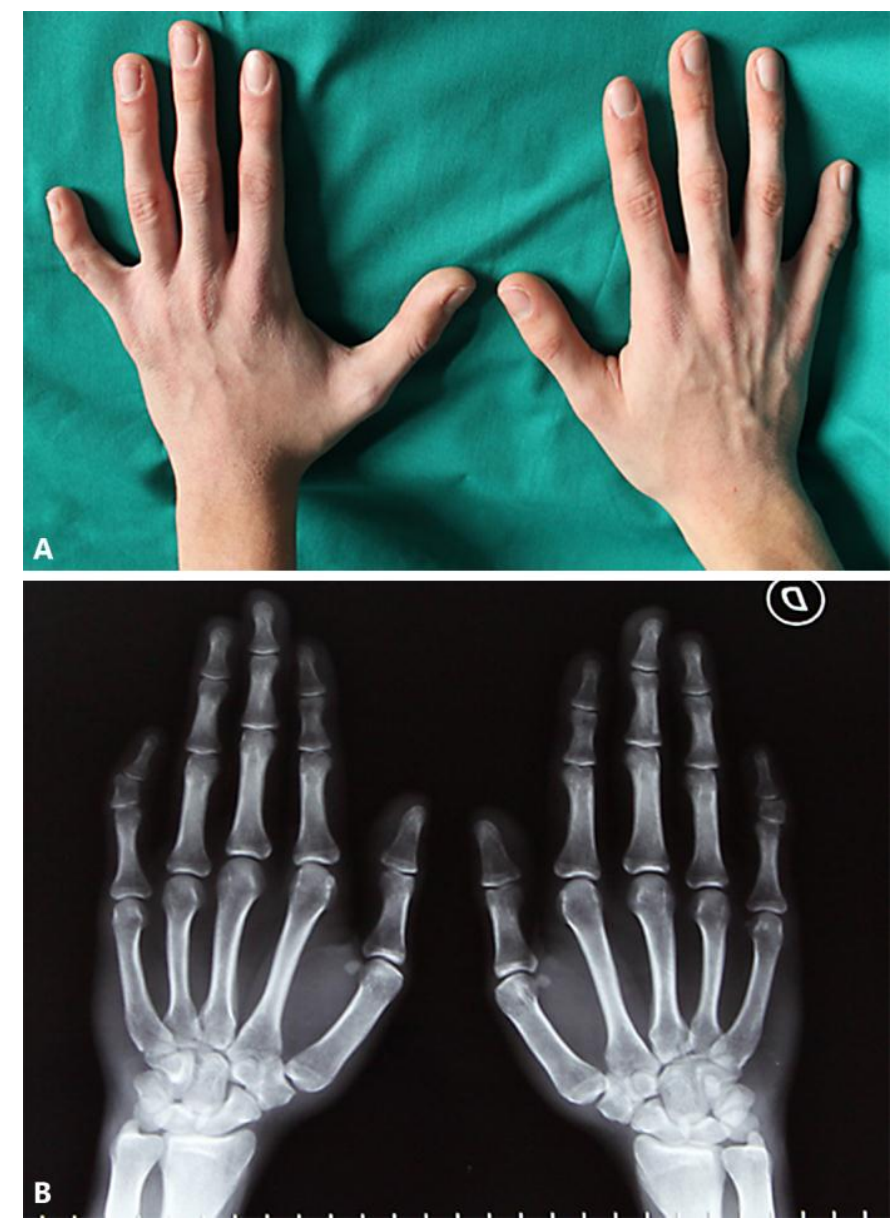

Fig. 3. The patient showed clinodactyly of the fifth finger of both hands (A), more evidently on the left side, confirmed by X-ray examination (B). 